\title{
Totally Chlorine Free (TCF) Bleaching of Wheat Straw Soda-Anthraquinone (AQ) Pulp with a Low Initial Kappa Number
}

\author{
Benping Lin, ${ }^{\mathrm{a}}$ Yanlan Liu, ${ }^{\mathrm{a}, *}$ Qijie Chen, ${ }^{\mathrm{a}}$ Lefan $\mathrm{Ma},{ }^{\mathrm{a}}$ and Jun $\mathrm{Xu}{ }^{\mathrm{b}}$ \\ The totally chlorine free (TCF) bleaching was studied for wheat straw \\ soda-anthraquinone $(A Q)$ pulp with a low kappa number of 8.3 using the \\ sequence of OQPO and OQPoPo. It was found that the oxygen \\ delignification on wheat straw pulp was still effective despite its low initial \\ kappa number. A delignification extent of $42 \%$ and an ISO brightness \\ increase of $10.9 \%$ were achieved. In the OQPO sequence, an ISO \\ brightness ceiling of $87.2 \%$ was achieved as the hydrogen peroxide $\left(\mathrm{H}_{2} \mathrm{O}_{2}\right)$ \\ charge was increased from $2 \%$ to $6 \%$ in the Po stage. In the OQPoPo \\ sequence, $2 \% \mathrm{H}_{2} \mathrm{O}_{2}$ was added in the second $\mathrm{Po}$ stage and the pulp \\ brightness exceeded $88 \%$ with a total charge of $4 \% \mathrm{H}_{2} \mathrm{O}_{2}$ in the $\mathrm{PoPO}$ \\ bleaching. Higher brightness values of $89.5 \%$ and $90.1 \%$ were obtained \\ under the total charges of $6 \%$ and $8 \% \mathrm{H}_{2} \mathrm{O}_{2}$, respectively. Compared to \\ the OQPo sequence, the higher brightness and equal viscosity of the \\ bleached pulps were obtained under the same total charge of $\mathrm{H}_{2} \mathrm{O}_{2}$ in the \\ OQPoPo sequence. The bleached pulps with high ISO brightness values \\ (greater than 88\%) retained acceptable strength properties. A slight \\ decrease of fiber length occurred as the bleaching sequences proceeded, \\ while the fiber width and curl index somewhat increased.
}

DOI: 10.15376/biores.17.1.952-961

Keywords: TCF bleaching; High brightness; Wheat straw; Soda-AQ pulp; Low kappa number

Contact information: a: School of Chemistry and Food Engineering, Changsha University of Science and Technology, Changsha, China; $b$ : State Key Laboratory of Pulp and Paper Engineering, South China University of Technology, Guangzhou, China; *Corresponding author: 343046856@qq.com

\section{INTRODUCTION}

Due to the shortages of wood resources in some countries such as China and India, agricultural waste from wheat or rice straw plays an important role in the local pulp and paper industry (Singh et al. 2011; Kaur et al. 2017; Sun et al. 2018). It has been determined that wheat straw could present a sustainable fiber source to supplement the use of wood fiber in producing different grades of papers. Many studies and enterprise applications have indicated that wheat straw pulp can be used for making printing paper, writing paper, packing paper, household paper, and so on (Guo et al. 2009; Hou et al. 2011; Zhang et al. 2011).

The wheat straw pulping process is facing some problems, including a lower alkaline recovery rate, higher waste water discharge levels, etc. (Dai and Zhai 2012; Rastegarfar et al. 2015; Kaur et al. 2017; Sun et al. 2018). The bleaching is also a critical process for wheat straw pulp. To achieve high brightness levels, the chlorine alkaline hypochlorite $(\mathrm{CEH})$ bleaching sequence has been conventionally used in wheat straw pulp mills. The absorbable organic halogen (AOX), especially the dioxins, released from $\mathrm{CEH}$ 
bleaching is well known as a potent carcinogen to humans (Reinstaller 2008; Wang et al. 2012). The open burning of straw waste has also been forbidden by the Chinese and Indian governments, since it will release noxious gases as well as particulate pollutants to the atmosphere (Sheng 2015; Kaur et al. 2017). Therefore, a cleaner production method for straw pulp is a key factor in making good use of wheat straw fiber resources. To replace the chlorinated bleaching of wheat straw pulp, total chlorine free (TCF) bleaching has been the subject of much research (Jun 2000; Huang et al. 2003; Roncero et al. 2003; Hedjazi et al. 2009; Salehi et al. 2014). However, it is hard to obtained wheat straw pulp with ISO brightness levels above $88 \%$ via TCF bleaching. No studies have been reported that address these issues. The chemical compositions of raw materials, as well as the pulping methods used, influence the pulp bleaching effects significantly. Even though there are some disadvantages of AQ use in pulping, as detailed by Hart et al. (2014), soda-anthraquinone (AQ) pulping is the most common method for wheat straw in pulp mills around the world. Wheat straw pulps made using different cooking conditions or pulping methods exhibit different behaviors when subjected to specific TCF bleaching sequences. The cooked wheat straw pulps with a lower kappa number might be beneficial for the development of brightness in TCF bleaching. The low kappa number of pulps, which indicate a lower residual lignin content, can also decrease the use of chemicals and the effluent discharge during the bleaching processes. It is generally considered that a low kappa number of pulp contributes to the implementation of TCF bleaching.

The objective of this study was to develop the TCF bleaching technology for wheat straw pulp to achieve a target ISO brightness over $88 \%$. To implement the modern TCF bleaching techniques, the OQPo and $\mathrm{OQP}$ oPo sequences were adopted for wheat straw soda-AQ pulp. Wheat straw pulp with a low kappa number of 8.3 was prepared under a suitable soda-AQ pulping process. The brightness, yield, viscosity, and fiber morphology of the bleached pulps, as well as the strength properties, were examined and analyzed during the experimental bleaching processes.

\section{EXPERIMENTAL}

\section{Raw Materials and Pulping}

The wheat straw was collected as an agricultural waste from farmland of northern China. Prior to the soda-AQ pulping experiments, the wheat straw was chopped into samples that were 3 to $5 \mathrm{~cm}$ in length. The digesting of the wheat straw was conducted under the following conditions: total alkali $(\mathrm{NaOH})$ charge of $16 \%$, AQ charge of $0.1 \%$, temperature of $160{ }^{\circ} \mathrm{C}$, solid-to-liquid ratio of $1: 15$, heating up time of $30 \mathrm{~min}$, and a heating preservation time at the maximum temperature of 60 min. After cooking, the wheat straw pulp was washed, screened, dewatered, and stored in a polyethylene bag at $4{ }^{\circ} \mathrm{C}$. Kappa number of unbleached pulp, which based on the consumption of $0.1 \mathrm{~N}$ potassium permanganate $\left(\mathrm{KMnO}_{4}\right)$ solution by one gram of oven-dried pulp under the specified conditions, was analyzed as per TAPPI T 236 om-06 (2006). The unbleached pulp with a kappa number of 8.3 was prepared for further bleaching studies.

\section{Bleaching}

The wheat straw pulp was bleached with the TCF bleaching sequences OQPo and OQPoPo. In these sequences, $\mathrm{O}$ represented oxygen $\left(\mathrm{O}_{2}\right)$ bleaching, $\mathrm{Q}$ represented chelating pretreatment, and Porepresented hydrogen peroxide $\left(\mathrm{H}_{2} \mathrm{O}_{2}\right)$ with oxygen at a high 
temperature and pressure. The bleaching procedure is outlined below.

Oxygen delignification $(O)$

The laboratory oxygen delignification was conducted in a 1-gallon high pressure reactor (Series 4520, Parr Instrument Company, Moline, USA) equipped with an oxygen gas inlet, a mixing stirrer, a cooling coil, and a temperature control system. The wheat straw pulp was loaded into the reactor after being sufficiently mixed with the charged chemicals shown in Table 1. When the reaction time was attained, the steam was discharged from the reactor and the reactor was cooled down. Then, the pulp was removed from the reactor, washed adequately with distilled water, dried, placed in a sealed plastic bag, and stored at $4{ }^{\circ} \mathrm{C}$ for future processing.

\section{Chelating stage $(Q)$}

A chelating pretreatment stage to eliminate the metallic ions in pulp was performed in a beaker with a stirring rate of $450 \mathrm{rpm}$. The process conditions of the $\mathrm{Q}$ stage are detailed in Table 1.

Oxygen reinforced peroxide bleaching stage ( $P_{o}$ and $\left.\mathrm{P}_{O} \mathrm{P}_{\mathrm{O}}\right)$

The peroxide bleaching stage was carried out in the same reactor used for the $\mathrm{O}$ stage. The oxygen was injected into the autoclave to reinforce the peroxide bleaching ability. The inner surface of the autoclave was covered with a Teflon coating (Parr Instrument Company, Moline, IL, USA) to isolate the pulp slurry from the metal shell. Once the first steps of Po1 stage were completed, the pulp was removed from the kettle. Next, the filtrates were collected for analysis of the residual peroxide. The pulp was adequately washed with distilled water, and the washed pulp from the first Po1 stage was applied to the second $\mathrm{P}_{\mathrm{O} 2}$ stage to achieve a higher brightness level. The bleaching conditions that were employed on the wheat straw pulp can be seen in Table 1.

Table 1. Experimental Conditions of the TCF Bleaching for the Wheat Straw Pulp

\begin{tabular}{|c|c|c|c|c|c|c|c|}
\hline Sample & $\begin{array}{l}\text { Time } \\
\text { (min) }\end{array}$ & $\begin{array}{c}\text { Temperature } \\
\left({ }^{\circ} \mathrm{C}\right)\end{array}$ & $\begin{array}{c}\text { Consistency } \\
(\%)\end{array}$ & $\begin{array}{c}\text { Total } \mathrm{H}_{2} \mathrm{O}_{2} \\
(\%)\end{array}$ & $\begin{array}{c}\mathrm{NaOH} \\
(\%)\end{array}$ & $\begin{array}{c}\text { DTPA } \\
(\%)\end{array}$ & $\begin{array}{c}\mathrm{O}_{2} \\
(\mathrm{MPa})\end{array}$ \\
\hline $\mathrm{O}$ & 60 & 100 & 10 & - & 4.0 & - & 0.7 \\
\hline $\mathrm{OQ}$ & 60 & 70 & 3 & - & - & 0.3 & - \\
\hline $\mathrm{OQPO}_{\mathrm{O}-1}$ & 90 & 100 & 10 & 2.0 & 2.0 & 0.2 & 1.0 \\
\hline OQPO1-2 & 90 & 100 & 10 & 4.0 & 3.0 & 0.2 & 1.0 \\
\hline $\mathrm{OQP}_{\mathrm{O}-3}$ & 90 & 100 & 10 & 6.0 & 4.0 & 0.2 & 1.0 \\
\hline $\begin{array}{c}\text { OQPO1- } \\
{ }_{1} \mathrm{P}_{\mathrm{O} 2}\end{array}$ & 90 & 100 & 10 & $4.0(2.0+2.0)$ & 2.0 & - & 0.7 \\
\hline $\begin{array}{l}\text { OQPO1- } \\
{ }_{2} \mathrm{P}_{\mathrm{O} 2}\end{array}$ & 90 & 100 & 10 & $6.0(4.0+2.0)$ & 2.0 & - & 0.7 \\
\hline $\begin{array}{c}\mathrm{OQP}_{\mathrm{O} 1-} \\
{ }_{3} \mathrm{P}_{\mathrm{O} 2}\end{array}$ & 90 & 100 & 10 & $8.0(6.0+2.0)$ & 2.0 & - & 0.7 \\
\hline
\end{tabular}

Notes: $0.5 \%$ magnesium sulfate $\left(\mathrm{MgSO}_{4}\right)$ was added in the $\mathrm{O}, \mathrm{P}_{\mathrm{O} 1}$ and $\mathrm{P}_{\mathrm{O} 2}$ stages to protect the carbohydrates. $3 \%$ sodium silicate $\left(\mathrm{Na}_{2} \mathrm{SiO}_{3}\right)$ was added in the $\mathrm{P}_{01}$ and $\mathrm{P}_{\mathrm{O}}$ stages as the hydrogen peroxide stabilizer. In the $\mathrm{OQP}_{\mathrm{O} 1} \mathrm{P}_{\mathrm{O} 2}$ sequence, a supplement bleaching of $\mathrm{P}_{\mathrm{O} 2}$ stage with charge of $2.0 \% \mathrm{H}_{2} \mathrm{O}_{2}$ was carried out based on OQPo1 with charge of $\mathrm{H}_{2} \mathrm{O}_{2}$ from $2.0 \%$ to $6.0 \%$. DTPA is diethylene triamine pentacetate acid. 


\section{Pulp Characterization}

The pulp fiber was dissolved in cupriethylenediamine solution (China National Pulp and Paper Research Institute Co. LTD, Beijing, China) to determine the viscosity, based on the TAPPI T 230 om-04 (2004). The concentrations of metal ions in pulp, including the calcium, magnesium, manganese, iron, and copper ions, were measured according to the TAPPI standard T266 om-02 (2002). The metal ions in diluted solution from the hydrogen chloride $(\mathrm{HCl})$ wetted ash of pulps were detected by inductively coupled plasma optical emission spectroscopy (ICP). The fiber length, width, fines content, curl index, and kink index of the wheat straw pulp were tested using a fiber morphology analyzer (Kajaani Fs-300; Metso, Helsinki, Finland). The concentration of residual $\mathrm{H}_{2} \mathrm{O}_{2}$ in the bleaching filtrates obtained after each Po stage were determined according to standard iodometric titration using ammonium molybdate solution as catalyst. The $\mathrm{H}_{2} \mathrm{O}_{2}$ consumption was calculated according to Eq. 1,

$$
\begin{array}{r}
\mathrm{H}_{2} \mathrm{O}_{2} \text { consumption }(\%)=\text { Initial } \mathrm{H}_{2} \mathrm{O}_{2} \text { charge }(\%)- \\
\text { Residual } \mathrm{H}_{2} \mathrm{O}_{2} \text { charge }(\%)
\end{array}
$$

The handsheets for the brightness test were prepared using the TAPPI standard T218 sp-02 (2002) and measured according to the TAPPI standard T452 (1999). A set of handsheets $\left(60 \mathrm{~g} / \mathrm{m}^{2}\right)$ were prepared according to the TAPPI standard T205 sp-02 (2002) for testing the physical strength properties. The handsheets were conditioned at a temperature range of $23 \pm 1{ }^{\circ} \mathrm{C}$ and a relative humility $50 \pm 2 \%$ for $48 \mathrm{~h}$. The tensile, burst, and tear indexes of the handsheets were tested according to the TAPPI standards T494, T414, and T403, respectively (1999), using an L\&W TH-1 instrument (Lorentzen \& Wettre, Stockholm, Sweden), an L\&W CE180 instrument (Lorentzen \& Wettre, Stockholm, Sweden), and a TMI tear strength meter (TMI Corporation, New Castle, DE, USA).

\section{RESULTS AND DISCUSSION}

\section{Effect of the $\mathrm{O}$ and $\mathrm{Q}$ Stages on the Pulp Properties}

Oxygen delignification has become an indispensable part of multi-stage TCF bleaching as a result of the environmental-friendly character, the low cost of reducing the lignin content, and the saving of chemicals in the subsequent bleaching stages (Bajpai 2012a; Li et al. 2015). It is typically used in the first stage of a TCF bleaching sequence. As illustrated in Table 2, the oxygen delignification was effectively performed on the unbleached wheat straw pulp with a low initial kappa number of 8.3. The kappa number was reduced to 4.8 , which meant that a delignification rate of $42 \%$ was achieved in the $\mathrm{O}$ stage. Furthermore, the viscosity of $965 \mathrm{~mL} \cdot \mathrm{g}^{-1}$ had been retained at a high level which was acceptable. The effective delignification was accompanied by an ISO brightness increase of $10.9 \%$. With the same charge of $4 \% \mathrm{NaOH}$, a delignification degree of $50 \%$ and the same level of pulp viscosity were achieved by Hedjazi et al. in the O stage bleaching of wheat straw AS/AQ pulp (Hedjazi et al. 2009).

Transition metal ions such as iron, manganese, and copper, cause drastic decomposition of $\mathrm{H}_{2} \mathrm{O}_{2}$ during peroxide bleaching and must be removed as far as possible prior to the P or Po stage. Abrantes et al. (2007) studied the effect of a chelating stage before the hydrogen peroxide stage in the TCF bleaching sequence applied to a giant reed kraft-anthraquinone pulp. The results showed higher pulp viscosity, less peroxide consumption, and higher pulp brightness when the chelating pretreatment was applied. The 
metal ions contents in the wheat straw pulp before and after the chelating treatment are illustrated in Table 2. Compared with the manganese and iron ions, the copper ions content was relatively high in the oxygen delignification pulp. However, the residual content of the copper ions was observed to be lower than that of the iron ions in the pulp after the Q stage. Even though the manganese ions content in the pulp was very low, most of them had been removed from the pulp during the chelating treatment. The calcium and magnesium ions, which were identified as a beneficial stabilizer of peroxide bleaching, were also removed to a high extent, as shown in Table 2 . On the other hand, the chelating treatment stage had improved the ISO brightness of the pulp by $4.2 \%$.

Table 2. Pulp Properties and Metal lons Content of the Unbleached, Oxygen Delignification, and Chelating Treatment Pulps

\begin{tabular}{|c|c|c|c|c|c|c|c|c|}
\hline \multirow{2}{*}{ Stage } & \multicolumn{3}{|c|}{ Pulp Properties } & \multicolumn{5}{c|}{ Metal lons Content } \\
\cline { 2 - 9 } & $\begin{array}{c}\text { Kappa } \\
\text { Number }\end{array}$ & $\begin{array}{c}\text { Brightness } \\
(\% \text { ISO) }\end{array}$ & $\begin{array}{c}\text { Viscosity } \\
\left(\mathrm{mL}^{-1}\right)^{-1}\end{array}$ & $\begin{array}{c}\text { Fe } \\
(\mathrm{ppm})\end{array}$ & $\begin{array}{c}\text { Mn } \\
(\mathrm{ppm})\end{array}$ & $\begin{array}{c}\mathrm{Cu} \\
(\mathrm{ppm})\end{array}$ & $\begin{array}{c}\text { Ca } \\
(\mathrm{ppm})\end{array}$ & $\begin{array}{c}\text { Mg } \\
(\mathrm{ppm})\end{array}$ \\
\hline Unbleached & 8.3 & 40.1 & 1189 & 55 & 11 & 185 & 1564 & 1554 \\
\hline $\mathrm{O}$ & 4.8 & 51.0 & 965 & 53 & 11 & 180 & 1420 & 2413 \\
\hline $\mathrm{Q}$ & 3.9 & 55.2 & 904 & 29 & 3 & 19 & 566 & 890 \\
\hline
\end{tabular}

\section{Effect of the Po and PoPo Bleaching Stages on the Pulp Properties}

The peroxide bleaching reinforced by oxygen is the core component of the TCF sequence. The short sequence of $\mathrm{OQPO}$ or $\mathrm{OQPOPO}_{\mathrm{O}}$ is practical for bleaching the wheat straw pulp to achieve a high final ISO brightness over $80 \%$. Both increasing the oxygen pressure and raising the temperature can shorten the bleaching time and get higher pulp brightness. Higher pressure makes it possible to raise the reaction temperature and avoid slurry boiling. The fundamental mechanism of delignification in peroxide bleaching was reviewed in detail by Bajpai (2012b). As can be seen in Fig. 1, during the single stage of oxygen reinforced peroxide bleaching process $(\mathrm{PO})$, the charges of the $\mathrm{H}_{2} \mathrm{O}_{2}$ and $\mathrm{NaOH}$ were stepwise increased. The brightness development was enhanced in the Po stage with a charge of $2 \% \mathrm{H}_{2} \mathrm{O}_{2}$, which resulted in a remarkable increase in the pulp ISO brightness from $55.2 \%$ to $84.3 \%$. Then, the pulp ISO brightness was further increased from $84.3 \%$ to $87.1 \%$ by increasing the amount of $\mathrm{H}_{2} \mathrm{O}_{2}$ from $2 \%$ to $4 \%$. The actual consumption of $\mathrm{H}_{2} \mathrm{O}_{2}$ was $1.14 \%$ and $2.91 \%$ respectively. However, when the charges of the $\mathrm{H}_{2} \mathrm{O}_{2}$ increased from $4 \%$ to $6 \%$, the ISO brightness level of the bleached pulp $(87.2 \%)$ remained unchanged, which indicated that a brightness ceiling might have been reached in the Po1 stage. Moreover, the actual consumption ratio of $\mathrm{H}_{2} \mathrm{O}_{2}$ increased from $72.75 \%$ (2.91/4.0) to $82.33 \%$ (4.94/6.0). Therefore, the hydrogen peroxide was unproductively decomposed, which indicated that the side reactions occurred. It was determined that the brightness of bleached pulp cannot be pushed up further using higher charges of $\mathrm{H}_{2} \mathrm{O}_{2}$ in the single bleaching process even under the drastic conditions of temperature and oxygen pressure.

To obtain the full bleached pulp with ISO brightness over $88 \%$, two-staged oxygen reinforced peroxide bleaching $\left(\mathrm{PoP}_{\mathrm{O}}\right)$ was applied. Supplemental peroxide bleaching of $\mathrm{Po}_{2}$ with a charge of $2.0 \% \mathrm{H}_{2} \mathrm{O}_{2}$ was carried out based on Po1. As illustrated in Fig. 1, the brightness of the bleached pulps in the PoPo process improved gradually, just as they did in the Po stage. With a total charge of $4 \% \mathrm{H}_{2} \mathrm{O}_{2}, 88 \%$ ISO brightness was exceeded in the PoPo bleaching stage. When the total charges of $6 \%$ and $8 \% \mathrm{H}_{2} \mathrm{O}_{2}$ were added, bleached pulps with ISO brightness levels of $89.5 \%$ and $90.1 \%$, respectively, were obtained. In other words, a higher level of brightness was achieved in the PoPo stage with an equivalent total 
charge of $\mathrm{H}_{2} \mathrm{O}_{2}$ as in the $\mathrm{P}_{\mathrm{O}}$ stage. It was apparent that partial supplement of $\mathrm{H}_{2} \mathrm{O}_{2}$ in twostage $\mathrm{PoP}_{\mathrm{O}}$ bleaching was more effective in raising the brightness than a one-time injecting of all $\mathrm{H}_{2} \mathrm{O}_{2}$ in the single $\mathrm{P}_{\mathrm{O}}$ stage.

Figure 1 also presents an interesting result of the $\mathrm{H}_{2} \mathrm{O}_{2}$ consumption. At the same dosage of $\mathrm{H}_{2} \mathrm{O}_{2}$, less consumption was observed in the PoPobleaching stage. This indicates that the filtrate after the $\mathrm{PoP}_{\mathrm{O}}$ bleaching contains more residual peroxide. It is generally recognized that $90 \%$ of the residual peroxide in bleaching effluent remains active. Assuming that the residual peroxide was equivalent to the fresh one, the effluent from the second stage can be recycled to the first stage in a two-stage bleaching system. Doing this could further reduce the cost of bleaching chemicals.

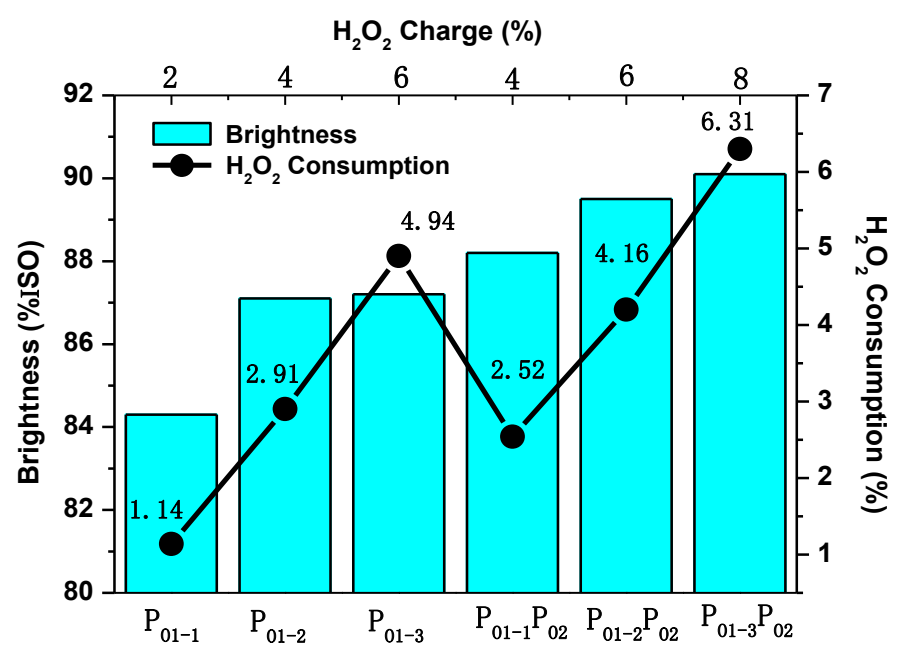

Fig. 1. Effect of the bleaching sequence and the $\mathrm{H}_{2} \mathrm{O}_{2}$ charge on the pulp brightness and the $\mathrm{H}_{2} \mathrm{O}_{2}$ consumption

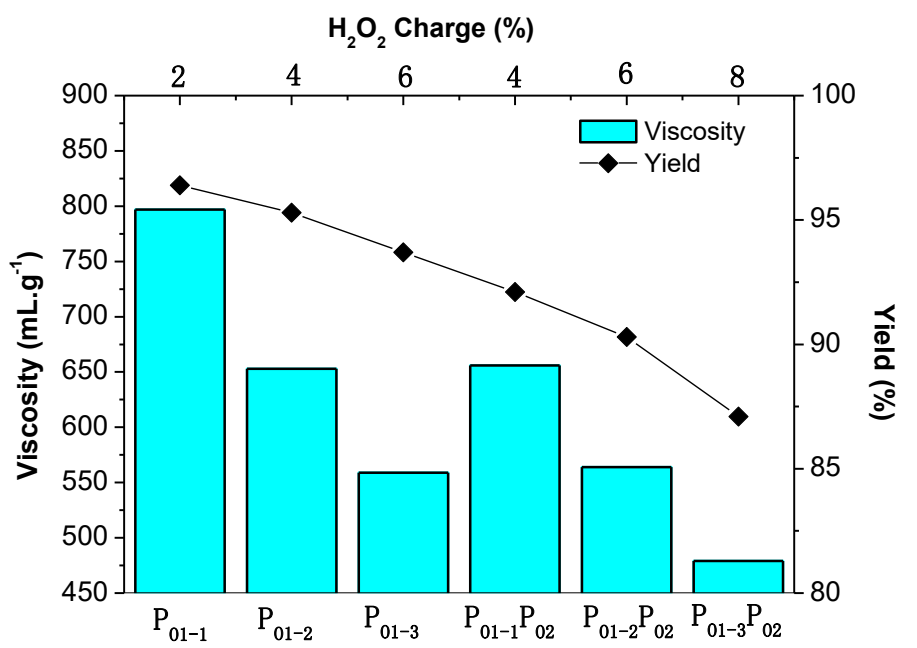

Fig. 2. Effect of the bleaching sequence and the $\mathrm{H}_{2} \mathrm{O}_{2}$ charge on the pulp viscosity and the yield

Under a given set of bleaching conditions, the pulp viscosity gives a reliable account of carbohydrate degradation. Degradation of the carbohydrates is a crucial factor affecting the strength properties of bleached chemical pulps. Figure 2 shows the determinations of the pulp viscosity and the total yield after Po and PoPo bleaching stages 
under different $\mathrm{H}_{2} \mathrm{O}_{2}$ charge levels. The pulp viscosity as well as the yield decreased as the $\mathrm{H}_{2} \mathrm{O}_{2}$ dosage increased. For the same dosage of $\mathrm{H}_{2} \mathrm{O}_{2}(4 \%$ and $6 \%)$, the pulp viscosity of the $\mathrm{Po}_{\mathrm{O}}$ and the $\mathrm{PoP}_{\mathrm{O}}$ was at the same level.

\section{Physical Properties of the Wheat Straw Pulp during the OQPoPo Bleaching Stage}

The physical properties of the wheat straw pulp during the OQPoPobleaching stage are listed in Table 3. The Canadian standard freeness (CSF) of the bleached pulp rapidly declined after the oxygen delignification and chelating pretreatment. Furthermore, the CSF of the pulp only changed slightly as the peroxide charge in PoPo stage increased. The lower degree of pulp freeness meant that the fiber flexibility increased and the pulp drainability decreased during the bleaching operations. The CSF of bleached pulps below $340 \mathrm{~mL}$ was low enough for paper mills to use them making paper directly even without any further beating or refining.

Table 3. Physical Properties of the Wheat Straw Pulps during the OQPoPo Bleaching Stage

\begin{tabular}{|l|c|c|c|c|c|}
\hline \multicolumn{1}{|c|}{ Sample } & $\begin{array}{c}\text { Brightness } \\
(\% \text { ISO })\end{array}$ & $\begin{array}{c}\text { Freeness } \\
(\mathrm{mL} \text { CSF })\end{array}$ & $\begin{array}{c}\text { Tensile Index } \\
\left(\mathrm{Nm} \cdot \mathrm{g}^{-1}\right)\end{array}$ & $\begin{array}{c}\text { Tear Index } \\
\left(\mathrm{mN} \cdot \mathrm{m}^{2} \cdot \mathrm{g}^{-1}\right)\end{array}$ & $\begin{array}{c}\text { Burst Index } \\
\left(\mathrm{Kpa} \cdot \mathrm{m}^{2} \cdot \mathrm{g}^{-1}\right)\end{array}$ \\
\hline Unbleached & 40.1 & 455 & 75.6 & 4.87 & 4.14 \\
\hline $\mathrm{O}$ & 51.0 & 413 & 69.2 & 5.04 & 3.89 \\
\hline $\mathrm{OQ}$ & 55.2 & 366 & 74.1 & 4.54 & 4.75 \\
\hline $\mathrm{OQP}_{01-1} \mathrm{P}_{\mathrm{O} 2}$ & 88.2 & 342 & 60.9 & 5.37 & 3.88 \\
\hline $\mathrm{OQP}_{\mathrm{O} 1-2} \mathrm{P}_{02}$ & 89.5 & 331 & 59.8 & 5.20 & 3.46 \\
\hline $\mathrm{OQP}_{\mathrm{O} 1-3} \mathrm{P}_{\mathrm{O} 2}$ & 90.1 & 320 & 54.2 & 5.13 & 3.34 \\
\hline
\end{tabular}

In general, the tensile and burst indexes of the bleached wheat straw pulps decreased while the tear indexes increased as the OQPoPo stages proceeded, which was consistent with previous research results (Hedjazi et al. 2009). Strength properties of pulp can indicate the paper making behaviors during its manufacturing process. The strength properties of the bleached pulps with the ISO brightness levels over $88 \%$ were monitored primarily. The tensile strength decreased as the $\mathrm{H}_{2} \mathrm{O}_{2}$ dosage increased, with minor reductions in the tear and burst strength properties. However, the strength losses for the bleached pulps were acceptable based on the previous pulps with good strength properties. Beating or refining treatment may also improve the strength properties of bleached pulp to a certain extent. Therefore, although the bleached pulp with high brightness had a lower viscosity, the pulp had retained acceptable tensile, burst, and tear strength properties.

\section{Fiber Analysis of the Wheat Straw Pulp During the OQPoPo Bleaching Stage}

Fiber morphology is another important characteristic of pulp, which naturally influence the physical properties of the final paper. The results of the measured fiber morphology of the pulp samples during the OQPoPo bleaching are shown in Table 4. Compared to mechanical refining, bleaching is commonly considered to have minimal effect on fiber morphology. As detailed in Table 4, a slight decrease of the fiber length occurred as the bleaching sequences proceeded. Meanwhile, the weighted width of the fibers increased slightly. The fines content was somewhat increasing. The bleaching also caused an overall increase of the curl index, which indicated that the fibers might have become softer. The fiber length of unbleached and bleached wheat straw pulp in current 
study was all above $1.00 \mathrm{~mm}$, which was longer than the non wood pulps reported by previous studies (Guo et al. 2009; Salehi et al. 2014; Li et al. 2015; Sharma et al. 2020). This might duo to the differences of pulping method, cooking conditions, raw material categories as well as pretreatments.

Table 4. Fiber Morphology Analysis of the Wheat Straw Pulp

\begin{tabular}{|l|c|c|c|c|c|c|}
\hline \multicolumn{1}{|c|}{ Sample } & $\begin{array}{c}\text { Brightness } \\
(\% \text { ISO })\end{array}$ & $\begin{array}{c}\text { Length } \\
\text { Weighted } \\
(\mathrm{mm})\end{array}$ & $\begin{array}{c}\text { Width } \\
\text { Weighted } \\
(\mu \mathrm{m})\end{array}$ & $\begin{array}{c}\text { Fines } \\
(\%)\end{array}$ & $\begin{array}{c}\text { Curl Index } \\
(\%)\end{array}$ & $\begin{array}{c}\text { Kink } \\
\text { Index } \\
\left(1 \cdot \mathrm{m}^{-1}\right)\end{array}$ \\
\hline Unbleached & 40.1 & 1.29 & 15.26 & 31.89 & 12.63 & 4535 \\
\hline $\mathrm{O}$ & 51.0 & 1.14 & 16.20 & 36.92 & 16.67 & 3300 \\
\hline $\mathrm{OQ}$ & 55.2 & 1.08 & 15.02 & 37.35 & 15.57 & 3113 \\
\hline $\mathrm{OQP}$ & 87.1 & 1.05 & 15.68 & 38.74 & 17.27 & 2297 \\
\hline $\mathrm{OQP}_{01-2} \mathrm{P}_{\mathrm{O} 2}$ & 89.5 & 1.00 & 17.19 & 40.43 & 18.09 & 3978 \\
\hline
\end{tabular}

\section{CONCLUSIONS}

1. The oxygen delignification $(\mathrm{O})$ was still effective despite the low kappa number of the wheat straw soda-AQ pulp. A delignification extent of $42 \%$ and an ISO brightness increase of $10.9 \%$ were observed.

2. Pulp with an ISO brightness greater than $88 \%$ with a total charge of $4 \% \mathrm{H}_{2} \mathrm{O}_{2}$ in the OQPoPo bleaching was achieved. Higher ISO brightness levels of $89.5 \%$ and $90.1 \%$ were obtained under the total charge of $6 \%$ and $8 \% \mathrm{H}_{2} \mathrm{O}_{2}$, respectively. It was feasible that wheat straw soda-AQ pulp with a lower kappa number can be bleached to high ISO brightness over $88 \%$ with the TCF bleaching sequence of OQPoPo.

3. The viscosity of the wheat straw pulp decreased gradually in the OQPoPo sequence. Despite its low viscosity, the bleached pulps with high ISO brightness levels over $88 \%$ retained acceptable tensile, burst, and tear strength properties. A slight decrease of the fiber length occurred as the bleaching sequences proceeded, while the fiber width and curl index increased slightly.

\section{ACKNOWLEDGMENTS}

The authors are grateful for the financial support from the Scientific Research Foundation of Hunan Provincial Education Department, China (Grant No. 17B010) and the Young Teacher Growth Plan Foundation of Changsha University of Science and Technology (Grant No. 2019QJCZ037). The financial support is greatly appreciated.

\section{REFERENCES CITED}

Abrantes, S., Amaral, E., Costa, A. P., Shatalov, A. A., and Duarte, A. P. (2007).

"Hydrogen peroxide bleaching of Arundo donax L. kraft-anthraquinone pulp - Effect of a chelating stage," Industrial Crops and Products 25(3), 288-293. DOI:

10.1016/j.indcrop.2006.12.006 
Bajpai, P. (2012a). “Chapter Three - Oxygen delignification,” in: Environmentally Benign Approaches for Pulp Bleaching (Second Edition), P. Bajpai (ed.), Elsevier Science Imprint, Boston, pp.19-52. DOI:10.1016/B978-0-444-59421-1.00003-X

Bajpai, P. (2012b). "Hydrogen peroxide bleaching," in: Environmentally Benign Approaches for Pulp Bleaching (Second Edition), P. Bajpai (ed.), Elsevier Science Imprint, Boston, Ch. 5. - pp. 97-129. DOI: 10.1016/B978-0-444-59421-1.00005-3

Dai, K., and Zhai, H. (2012). "Effect of black liquor replacement in wheat straw soda-AQ cooking and lignin structure of pulps," TAPPI Journal 11(5), 43-47. DOI: 10.32964/tj11.5.43

Guo, S., Zhan, H., Zhang, C., Fu, S., Heijnesson-Hulten, A., Basta, J., and Greschik, T. (2009). "Pulp and fiber characteristics of wheat straw and eucalyptus pulps - A comparison," BioResources 4(3), 1006-1016.

Hart, P. W., and Rudie, A.W. (2014). "Anthraquinone - A review of the rise and fall of a pulping catalyst," TAPPI Journal 13(10), 23-31. DOI: 10.32964/tj13.10.23

Hedjazi, S., Kordsachia, O., Patt, R., Latibari, A. J., and Tschirner, U. (2009). “Alkaline sulfite-anthraquinone (AS/AQ) pulping of wheat straw and total chlorine free (TCF) bleaching of pulps," Industrial Crops and Products 29(1), 27-36. DOI: 10.1016/j.indcrop.2008.03.013

Hou, Q., Yang, B., Liu, W., Liu, H., Hong, Y., and Zhang, R. (2011). “Co-refining of wheat straw pulp and hardwood kraft pulp," Carbohydrate Polymers 86(1), 255-259. DOI: 10.1016/j.carbpol.2011.04.040

Huang, G., Zhang, Z., He, C., and Wang, S. (2003). "Hydrogen peroxide bleaching of wheat straw pulp in high pressure and high temperature," China Pulp and Paper 22(9), 1-4.

Jun, Q. (2000). "A study on the total chlorine-free bleaching of wheat straw pulp," China Pulp and Paper (3), 6-10.

Kaur, D., Bhardwaj, N. K., and Lohchab, R. K. (2017). "Prospects of rice straw as a raw material for paper making," Waste Management 60, 127-139. DOI: 10.1016/j.wasman.2016.08.001

Li, Z., Li, J., Xu, J., and Mo, L. (2015). "Clean bleaching engineering practice for Bagasse pulp: Totally chlorine free and elemental chlorine free bleaching realized with the same production line," BioResources 10(2), 2667-2680. DOI: 10.15376/biores. 10.2.2667-2680

Rastegarfar, N., Behrooz, R., and Bahramifar, N. (2015). "Electrocoagulation treatment of black liquor from soda-AQ pulping of wheat straw," Environmental Monitoring and Assessment 187(45), 1-9. DOI: 10.1007/s10661-014-4245-0

Reinstaller, A. (2008). "The technological transition to chlorine free pulp bleaching technologies: Lessons for transition policies," Journal of Cleaner Production 16(1), S133-S147. DOI: 10.1016/j.jclepro.2007.10.020

Roncero, M. B., Torres, A. L., Colom, J. F., and Vidal, T. (2003). "TCF bleaching of wheat straw pulp using ozone and xylanase. Part A: Paper quality assessment," Bioresource Technology 87(3), 305-314. DOI: 10.1016/S0960-8524(02)00224-9

Salehi, K., Kordsachia, O., and Patt, R. (2014). "Comparison of MEA/AQ, soda and soda/AQ pulping of wheat and rye straw," Industrial Crops and Products 52, 603610. DOI: 10.1016/j.indcrop.2013.11.014

Singh, S., Dutt, D., and Tyagi, C. H. (2011). "Complete characterization of wheat straw (Triticum aestivum PBW-343 L. Emend. Fiori \& Paol.) - A renewable source of fibers for pulp and papermaking," BioResources 6(1), 154-177. DOI: 


\subsection{6/biores.6.1.154-177}

Sharma, N., Tripathi, S. K., and Bhardwaj, N. K. (2020). "Utilization of sarkanda for making pulp and paper using elemental chlorine free and total chlorine free bleaching processes," Industrial Crops and Products 149, article no. 112316. DOI: 10.1016/j.indcrop.2020.112316

Sheng, J. (2015). "The crops straw opening burning control research based on the government-farmer-enterprise cooperation game," Chinese Journal of Agricultural Resources and Regional Planning 36(4), 48-53. DOI: 10.7621/cjarrp.10059121.20150407

Sun, M., Wang, Y., and Shi, L. (2018). "Environmental performance of straw-based pulp making: A life cycle perspective," The Science of the Total Environment 616-617, 753-762. DOI: 10.1016/j.scitotenv.2017.10.250

TAPPI T205 sp-02. (2002). "Forming handsheets for physical tests of pulp," TAPPI Press, Atlanta, GA.

TAPPI T218 sp-02. (2002). "Forming handsheets for reflectance tests of pulp," TAPPI Press, Atlanta, GA.

TAPPI T230 om-06. (2004). "Viscosity of pulp (capillary viscometer method)," TAPPI Press, Atlanta, GA.

TAPPI T236 om-06. (2006). “Kappa number of pulp,” TAPPI Press, Atlanta, GA.

TAPPI T266 om-02. (2002). "Determination of sodium, calcium, copper, iron and manganese in pulp and paper by atomic absorption spectroscopy," TAPPI Press, Atlanta, GA.

TAPPI T403 om-99. (1999). "Bursting strength of paper," TAPPI Press, Atlanta, GA.

TAPPI T414 om-99. (1999). "Internal tearing resistance of paper (Elmendorf-type method)," TAPPI Press, Atlanta, GA.

TAPPI T452 om-99. (1999). "Brightness of pulp, paper, and paperboard (directional reflectance at $457 \mathrm{~nm})$, , TAPPI Press, Atlanta, GA.

TAPPI T494 om-99 (1999). "Tensile properties of paper and paperboard (using constant rate of elongation apparatus)," TAPPI Press, Atlanta, GA.

Wang, X., Ni, Y., Zhang, H., Zhang, X., and Chen, J. (2012). "Formation and emission of PCDD/Fs in Chinese non-wood pulp and paper mills," Environmental Science \& Technology 46(21), 12234-12240. DOI: 10.1021/es303373b

Zhang, H., He, Z., and Ni, Y. (2011). "Improvement of high-yield pulp properties by using a small amount of bleached wheat straw pulp," Bioresource Technology 102(3), 2829-2833. DOI: 10.1016/j.biortech.2010.10.053

Article submitted: August 25, 2021; Peer review completed: September 18, 2021;

Revised version received and accepted: December 9, 2021; Published: December 15, 2021.

DOI: 10.15376/biores.17.1.952-961 